\title{
AVALIAÇÃO DA PRODUTIVIDADE DA CENTRAL DE RECEBIMENTO DE EMBALAGENS VAZIAS DE AGROTÓXICOS DE ITUVERAVA-SP POR MEIO DE INDICADORES DE PERFORMANCE
}

\author{
BARBOSA, Aline Marques ${ }^{1}$ \\ PEREIRA, Regina Eli de Almeida²
}

RESUMO: No ano de 1999 com o apoio da Associação Nacional de Defesa Vegetal - ANDEF, foi criada a $3^{\text {a }}$ Central de Recebimento de Embalagens Vazias de Agrotóxicos do país, em Ituverava. Em 2002, entra em funcionamento o Instituto Nacional de Processamento de Embalagens Vazias - inpEV, com a função de gerir o sistema de destinação final de embalagens vazias de agrotóxicos. O mesmo se desenvolveu com o auxílio de uma consultoria especializada, uma ferramenta denominada "indicadores de performance", com o objetivo de medir, nas unidades de recebimento de todo o país, a produtividade, dentre outros parâmetros. O presente trabalho foi desenvolvido em 12 meses, e foram comparados os dados do primeiro semestre de 2005 com os mesmos obtidos, mensalmente, no primeiro semestre de 2006. O método utilizado foi o quadro de medição desenvolvido por Alcides Torres de Miranda e inpEV. (MIRANDA, 2004; INPEV, 2004). Dentre os parâmetros avaliados, pôdese concluir que: o número de embalagens passíveis de serem enfardadas se manteve constante nos dois anos considerados; a relação entre a quantidade de embalagens recebidas e enfardadas foi menos consistente no ano de 2006, com conseqüente redução no numero de cargas de Pead expedidas neste ano; em 2006, houve menor eficiência entre materiais recebidos e enfardados; redução na capacidade de enfardamento, consequiência da redução do enfardamento por tonelada/homem e homens/ mês acumulados no mesmo ano.

Palavras-chave: Embalagem. Produtividade. Indicadores.

SUMMARY: In the year of 1999 with the support of the National Association of Vegetal Defense - ANDEF was created the $3^{\text {rd }}$ Empty Agrotoxic Packing Receiving Central of the country, in Ituverava. In , inpEV enters in functioning the National Institute of Processing of Empty Packings -, with the function managing the final system of destination of empty packing of agrotoxics. The same was it developed with the aid of a specialized consulter, a called tool "indicating of performance", with the objective to measure all in the units of act of receiving of the country, the productivity amongst other parameters. The present work was developed in 12 months, had been compared the gotten data of the first semester of 2005 with the same ones monthly in the first semester of 2006. The used method was the picture of measurement developed for Alcides Torres de Miranda and inpEV. (MIRANDA, 2004; INPEV, 2004). Amongst the evaluated parameters it could be concluded that: the relation enters the amount of received packings and processed it was less consistent in the year of 2006, with consequent reduction in I number it of forwarded loads of Pead in this year; in 2006 it had minor efficiency between received and processed materials; reduction in the packing up capacity, consequence of the reduction of the packing up for ton/man and men month accumulated in the same year.

Keywords: Packing. Productivity. Pointers.

1 Pós graduanda em Educação Ambiental e responsabilidade social. Bacharel em Administração- Agronegócios. E-mail: aline.mbarbosa@yahoo.com.br

2 Mestre em Fitopatologia. Professora na Faculdade "Dr. Francisco Maeda". Fundação Educacional de Ituverava. E-mail: fito.fafram@feituverava.com.br 


\section{INTRODUÇÃO}

No ano de 1999 com o apoio da Associação Nacional de Defesa Vegetal - ANDEF foi criada a $3^{\text {a }}$ Central de Recebimento de Embalagens Vazias de Agrotóxicos do país, em Ituverava, visando sanar problemas ambientais e tentar resolver o descarte de embalagens vazias de agrotóxicos dos agricultores do município e demais cidades do entorno.

Em 2002 após a instauração da Lei 9.974/00, entra em funcionamento o Instituto Nacional de Processamento de Embalagens Vazias - inpEV, com a função de gerir o sistema de destinação final de embalagens vazias de agrotóxicos. Como a essência do sistema de devolução de embalagens é a integração entre os processos de recebimento e destinação final, o Instituto trabalha para monitorar as atividades envolvidas nessa cadeia, cuidando para que todas as etapas sejam bem-sucedidas protegendo o meio ambiente e a saúde humana. (INPEV, 2005)

Foi desenvolvida então pelo inpEV, com o auxílio de uma consultoria especializada uma ferramenta denominada "indicadores de performance". O objetivo desses indicadores é medir nas unidades de recebimento de todo país, a produtividade, eficiência e eficácia dentre outros parâmetros. Em 2005 a Central de Ituverava adotou este sistema de medição de desempenho possibilitando por meio desta ferramenta, acompanhar os processos e identificar possíveis falhas ou acertos para melhorar a qualidade das operações.

No presente trabalho buscou-se por meio da comparação dos indicadores de performance obtidos nos primeiros semestres de 2005 e 2006, obter informações que mostrassem se houve melhora ou decréscimo no desempenho dos trabalhos e atividades realizados na central.

\section{REVISÃO DE LITERATURA}

\subsection{DESTINAÇÃO FINAL DAS EMBALAGENS VAZIAS DE AGROTÓXICOS}

Um dos principais problemas da utilização de agrotóxicos é o descarte das embalagens vazias. Em nível mundial, a recomendação era para que se enterrasse ou queimasse estas embalagens, o que muitas vezes resultava em danos ao meio ambiente. Em 6 de junho de 2000 a lei $\mathrm{n}^{\mathrm{o}} 9.974$, complementou a lei $\mathrm{n}^{\mathrm{o}} 7.802$ de junho de 1989 e o decreto $\mathrm{n}^{\mathrm{o}} 4.074$ de janeiro de 2002 regulamentou esta lei. A nova lei disciplina a destinação final das embalagens vazias de agrotóxicos e fixa responsabilidades para o agricultor, revendedor, fabricante e governo na questão de educação e comunicação, com punições que variam desde o pagamento de multa ao enquadramento dos infratores na lei de crimes ambientais. Prevê também o recolhimento e reciclagem ou incineração do material recolhido, conforme a possibilidade de descontaminação, o que permitiu a implantação de uma rede de unidades de recebimento de embalagens no Brasil, o que hoje ajuda a reduzir o número de embalagens abandonadas em lavouras, estradas e mananciais de água. (ROCHA, 2004 citado por VIANA, 2005)

De acordo com Associação Nacional de Defesa Vegetal - ANDEF (2006) por definição 
segundo a NBR 13.968, existem 02 tipos de embalagens passíveis de serem devolvidas: as embalagens laváveis, aquelas embalagens rígidas (plásticas, metálicas e de vidro) que acondicionam formulações líquidas de agrotóxicos para serem diluídas em água; e as não laváveis: embalagens flexíveis (sacos ou saquinhos de plásticos, de papel), metalizadas, mistas ou de outro material flexível e aquelas embalagens rígidas que não utilizam água como veículo de pulverização (por exemplo, tratamento de sementes); incluem-se nesta definição as embalagens secundárias não contaminadas rígidas ou flexíveis que acondicionam embalagens primárias não entrando em contato direto com os agrotóxicos (por exemplo, caixas de papelão).

As embalagens rígidas de plástico podem ser fabricadas com polietileno de alta densidade (PEAD), polietileno co-extrudado (COEX) ou polietileno tereftalato (PET); as tampas plásticas das embalagens são normalmente de polipropileno (PP). (GERASSI, 1998 citado por VIANA, 2005)

A embalagem PEAD, é a segunda resina mais reciclada no mundo. Esta resina tem alta resistência a impactos e aos agentes químicos. É identificada através das siglas HDPE (high density polyethylene), PE (polietileno) ou PEAD. Levando o número 2 estampado no fundo da embalagem. O PET possui excelente barreira para gases e odores, são identificados através da sigla PET ou PETE estampada na parte externa do recipiente. É uma estrutura monocamada identificada pelo número 1. O COEX, ou coextrusão também é conhecido pela sigla EVPE. É identificado através das siglas COEX, EVPE ou PAPE (poliamida polietileno). Seu número de identificação é o 7. O PP é identificado através do número 5 estampado no fundo das embalagens. A embalagem metálica mais utilizada é o balde metálico de folha de aço. Este recipiente embora seja o mais comum dentre as embalagens metálicas, representa apenas $10 \%$ de todo o volume de embalagens no Brasil. (INPEV, 2005 citado por VIANA, 2005)

\subsection{MEDIÇÃO DE DESEMPENHO}

Depois de uma operação ter medido seu desempenho, usando um conjunto de medidas parciais, ela precisa fazer um julgamento sobre se seu desempenho: bom, mau, ou indiferente. Há diversas formas de fazer isso, cada uma das quais envolve comparação do nível de desempenho atualmente atingido com algum tipo de padrão. (SLACK et al, 1999)

Segundo Côrrea; Côrrea (2005) medição de desempenho pode ser definida como o processo de quantificação da eficiência e da eficácia das ações tomadas por uma operação. Segundo os mesmos autores existem dois propósitos para avaliação de desempenho:

- Ser essencial para a gestão das operações e ser parte integrante do ciclo de planejamento e controle,

- Estabelecer um sistema adequado de avaliação de desempenho.

Segundo Pontes (1991), um gerente, ao administrar tem que planejar, organizar, liderar e controlar. Grande parte do controle é a garantia do desempenho eficiente dos indivíduos que fazem parte da sua unidade, que é feito através da Avaliação de Desempenho. A Avaliação de 
Desempenho visa acompanhar o trabalho e objetivos propostos aos indivíduos, e dar "feedback" a essas pessoas com vistas a torná-las motivadas e produtivas. Portanto, deve analisar o comportamento do colaborador e não da pessoa. Medição de desempenho é o processo de quantificar ação, em que medição é o processo de quantificação que leva ao desempenho (NEELY et al., 1995 citado por CORRÊA; CORRÊA, 2005).

As medições serão realizadas através do gerenciamento de um "Quadro de Medição" (MIRANDA, 2004; INPEV, 2004) que demonstra mensalmente o desempenho da Central, podendo dessa forma quantificar a eficiência, a eficácia e outros parâmetros nas tarefas realizadas. Esse quadro e os gráficos decorrentes serão utilizados como uma ferramenta administrativa gerencial.

De acordo com Corrêa; Corrêa (2005), normalmente associada aos conceitos de qualidade total, a melhoria contínua ou kaizen, é uma abordagem evolutiva, incremental, mais que radical. Com uma filosofia de transferir a responsabilidade pela qualidade aos funcionários de produção e estabelecer metas ambiciosas, o espírito é incentivar os colaboradores a continuamente usar as ferramentas da qualidade para procurar formas de melhorar passo a passo a qualidade do que fazem nos processos existentes. A expectativa do kaizen é de que os benefícios principais sejam obtidos ao longo do tempo.

\subsection{PRODUTIVIDADE, EFICIÊNCIA E EFICÁCIA}

\subsubsection{PRODUTIVIDADE}

O critério mais simples para avaliar a performance de um sistema é a produtividade. A produtividade de um sistema é definida como a relação entre os resultados obtidos (ou produção) e os recursos utilizados. Todo sistema tem um índice de produtividade, que se verifica com a contagem da quantidade produzida por unidade de recursos. Produtividade é uma das traduções mais conhecidas da idéia de performance. Esse conceito não deve ser confundido com o de eficiência que é a relação entre e os recursos previstos e aqueles realmente utilizados. Muitas vezes as duas palavras são usadas como sinônimos. A eficiência não leva em conta o aproveitamento, ou qualidade, dos itens produzidos. Por essa e outras razões é que a performance deve ser avaliada pelo conjunto dos seus diversos critérios: produtividade, eficiência, eficácia, qualidade, qualidade de vida no trabalho, inovação e rentabilidade. (MAXIMIANO, 2000)

\subsubsection{EFICIÊNCIA}

A eficiência de um sistema depende de como seus recursos são utilizados. Eficiência significa:

- A relação entre os recursos previstos para realizar determinada tarefa e os realmente utilizados. 
- Realizar tarefas de maneira inteligente, com o mínimo de esforço e com o melhor aproveitamento possível de recursos.

Eficiência é um princípio de administração de recursos, mais que uma simples medida de desempenho. O princípio geral da eficiência é o da relação entre esforço real e o previsto. Quanto menor o esforço necessário em relação ao previsto para produzir um resultado, mais eficiente é o processo. A antítese da eficiência é o desperdício. (MAXIMIANO, 2000)

\subsubsection{EFICÁCIA}

Eficácia é o conceito de desempenho que se relaciona com os objetivos e resultados. Eficácia significa:

- Grau de coincidência dos resultados em relação aos objetivos.

- Capacidade de um sistema, processo, produto ou serviço de resolver um problema.

- Fazer as coisas certas.

- Sobrevivência.

Eficácia é a relação entre resultados e objetivos, ou seja, entre o que foi realmente alcançado e o que era previsto.

Para avaliar o grau de eficácia de um sistema, é necessário saber quais são os objetivos e quais os resultados de fato alcançados.

Os objetivos relevantes para a idéia de eficácia relacionam-se com o ambiente da organização. Compreender o ambiente, suas necessidades, desafios e oportunidades são uma habilidade de vital importância para quem administra organizações. (MAXIMIANO, 2000)

\section{MATERIAL E MÉTODOS}

O trabalho foi desenvolvido na Central de Recebimento de Embalagens Vazias de Agrotóxicos de Ituverava-SP, situado à Rodovia Jerônimo Nunes Macedo Km 01 pertencente à Fundação Educacional de Ituverava e gerenciada pela Faculdade de Agronomia Dr. Francisco Maeda (FAFRAM). Os dados do $1^{\circ}$ semestre de 2005 foram comparados aos mesmos obtidos no $1^{\circ}$ semestre de 2006, portanto totalizando 12 meses em dois anos de avaliação.

O método utilizado foi o quadro de medição desenvolvido por Alcides Torres de Miranda e inpEV com dados de produtividade coletados mensalmente na Central. (MIRANDA, 2004; INPEV, 2004).

Os parâmetros avaliados foram estabelecidos a partir do Procedimento Operacional Padrão de Unidades de Recebimento - POPi do inpEV nos primeiros semestres (janeiro a junho) de 2005/2006 e, no final, os resultados foram comparados.

Dentro deste critério, os seguintes parâmetros foram avaliados:

- Produtividade global (enfardado/recebido): este parâmetro indica a relação 
entre mensal entre a quantidade de materiais recebidos e enfardados, incluindo neste contexto apenas as embalagens tríplice lavadas. Quanto mais próxima for a quantidade entre recebido e enfardado, maior a eficiência do processo, melhor o desempenho da Central no que se refere à diminuição do volume e consequentemente a adequação de suas instalações e procedimentos operacionais. Se a Central não consegue equilibrar a compactação com o recebimento, as suas instalações provavelmente terão que ser ampliadas ou os seus recursos humanos ou materiais devem ser aumentados, ou mudados os seus procedimentos operacionais.

- Produtividade no enfardamento: análise mais detalhada da produtividade por tonelada/pessoa e homens/mês acumulados, ou seja, a quantidade de embalagens enfardadas dividida pelo número de homens que trabalharam no mês e também a quantidade processada acumulada dividida pelo número de homens acumulados até o mês.

- Eficiência acumulada (enfardado/recebido): mostra a relação entre as quantidades de materiais enfardados e recebidos até o mês em porcentagem.

- Eficácia (enfardado/capacidade): demonstra em porcentagem a variação entre o material enfardado (dado real) e a capacidade de projeto de enfardamento da central (dado previsto).

\section{RESULTADOS E DISCUSSÃO}

As avaliações da performance estão apresentadas na forma de gráficos que foram gerados automaticamente na medida em que os dados coletados foram lançados no quadro de medição. Portanto avaliando os dados de cada gráfico é possível relatar se houve melhoria no desempenho da Central para aquele determinado critério.

A relação entre embalagens recebidas e enfardadas em cada mês está sendo apresentada na Figura 1. As linhas de recebido e enfardado no ano de 2005 encontraram-se mais próximas uma da outra durante todo o período, enquanto que no mesmo período em 2006 foi possível notar uma maior, distância destas linhas, principalmente no mês de abril. Este fato indica uma menor eficiência do processo o que pode estar ligado à adoção de uma nova tecnologia implantada na Central em dezembro de 2005. Até então os funcionários faziam a amarração dos fardos com arame, e a partir desta data passaram a trabalhar com fitas de plástico, conforme recomendação do inpEV (Figura 1). A mudança na amarração possivelmente quebrou a rotina existente no enfardamento devido à falta de prática no processo, culminando em menor quantidade de fardos produzidos em 2006. Outro fator que dever ser considerado seria um possível desvio do pessoal de prensagem para as operações de recebimento. O recebimento do mês 4 sobe e o enfardamento diminui. 


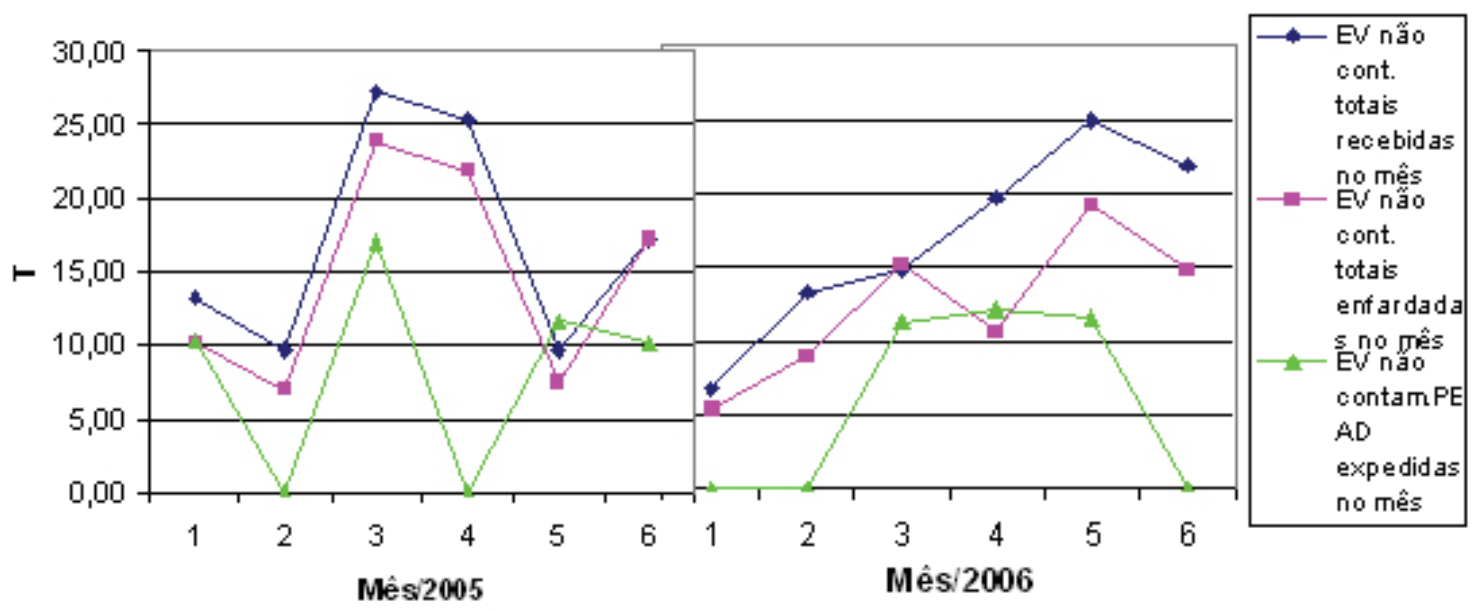

Figura 1: Comparação da quantidade total de materiais recebidos, enfardados e quantidade de Pead expedidos nos primeiros semestres de 2005 e 2006.

Em 2006, observa-se que a distância entre recebido e enfardado é bastante irregular sendo maior no mês de abril, com uma queda no enfardamento, apesar do aumento do recebimento. É possível notar também que o enfardamento menos consistente no ano de 2006 resultou em uma carga a menos de Pead destinado, em comparação ao mesmo período do ano passado.

Na Figura 2 foi avaliada a eficiência acumulada do processo com relação ao total enfardado e recebido até o mês de junho. Como já comentado anteriormente, no ano de 2006, a eficiência acumulada baixou em relação a 2005 numa média de 5\% (de 80 para 75\%).

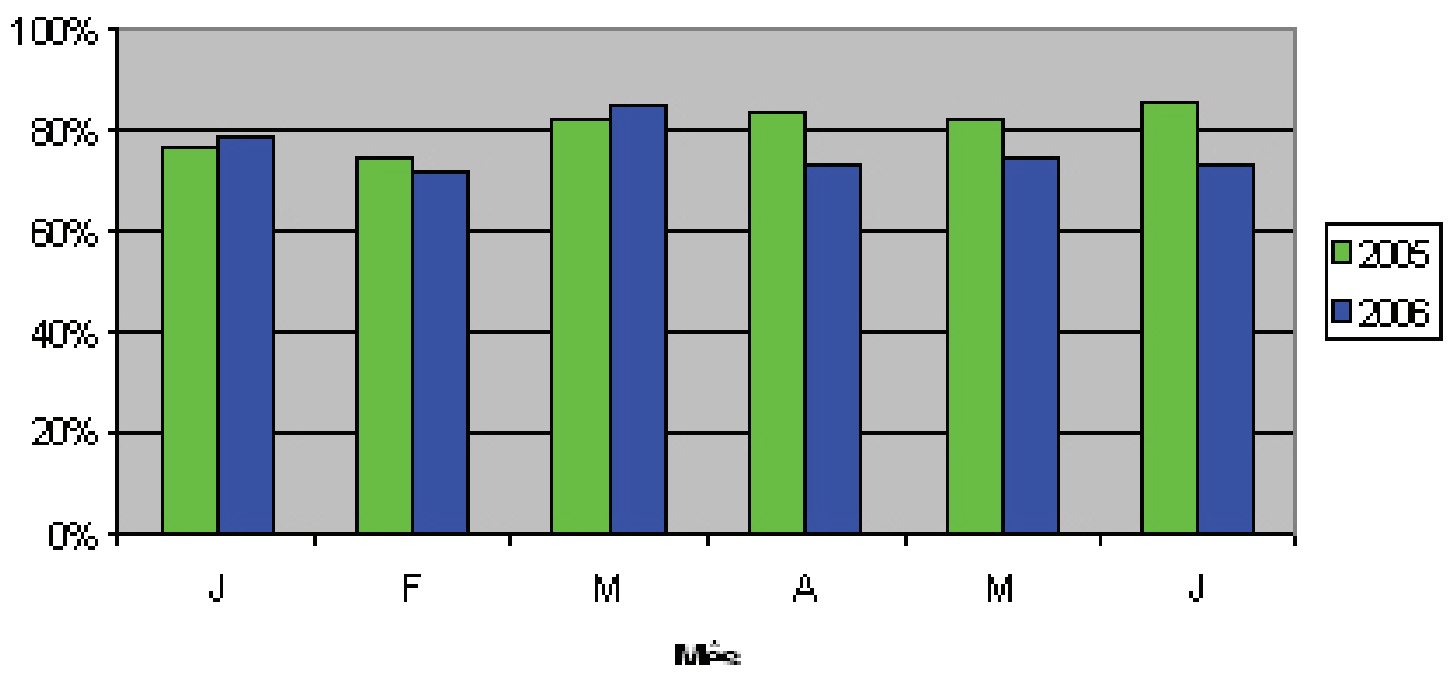

Figura 2: Comparação da eficiência dos materiais recebidos e enfardados até o mês em 2005 e 2006.

Baseado no fato de que o número de funcionários e a quantidade de embalagens recebidas foram razoavelmente as mesmas nos períodos considerados, pode-se concluir que a redução na eficiência foi provavelmente causada por uma menor produtividade do enfardamento. Já em maio foram tomadas algumas atitudes para melhorar a produtividade. Diante da problemática 
indicada, tomou-se a atitude de fazer reuniões periódicas juntamente com os funcionários a fim de estabelecer metas, tentando aumentar a relação entre recebido e enfardado.

De modo semelhante, a Figura 3 demonstra a oscilação da eficácia no enfardamento mensal em relação à meta anual (150 toneladas/ano) de enfardamento da Central, nos dois anos. Em 2005 observa-se que o desempenho foi 18\% mais eficaz que no mesmo semestre de 2006.

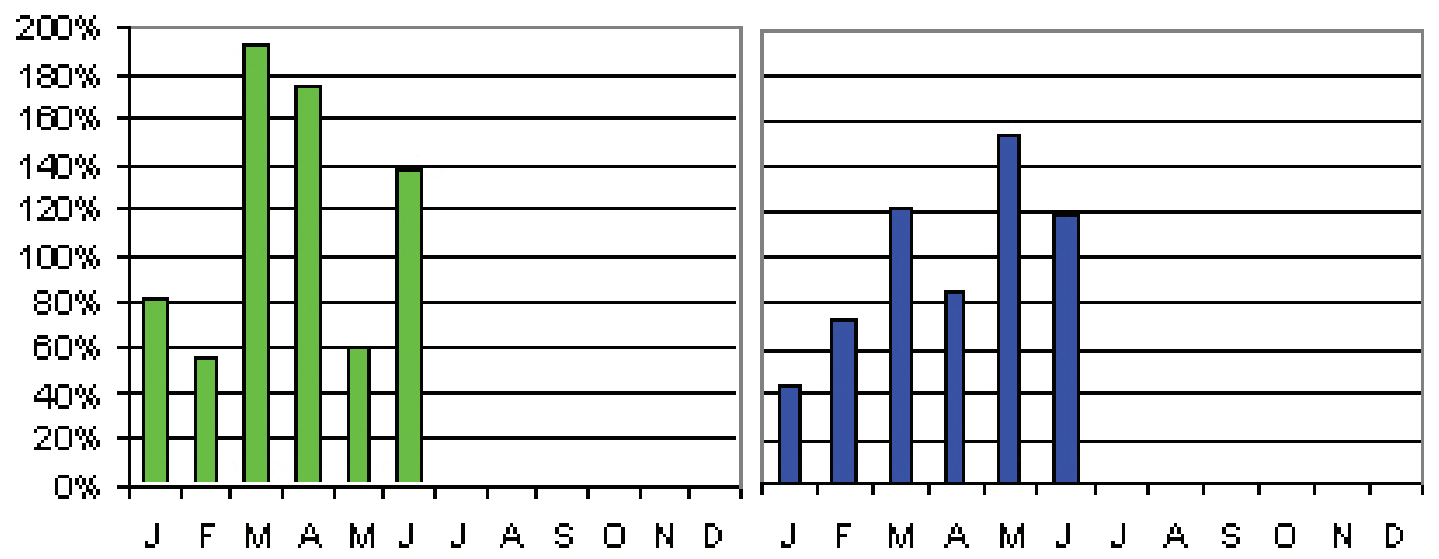

Figura 3: Comparação da quantidade de material enfardado por mês em relação à capacidade de enfardamento da central nos primeiros semestres de 2005 e 2006.

Avaliando-se a quantidade de embalagens enfardadas por pessoa e por homens mês acumulados, Figura 4, notou-se um leve decréscimo 17\% e 16\% respectivamente em 2006.

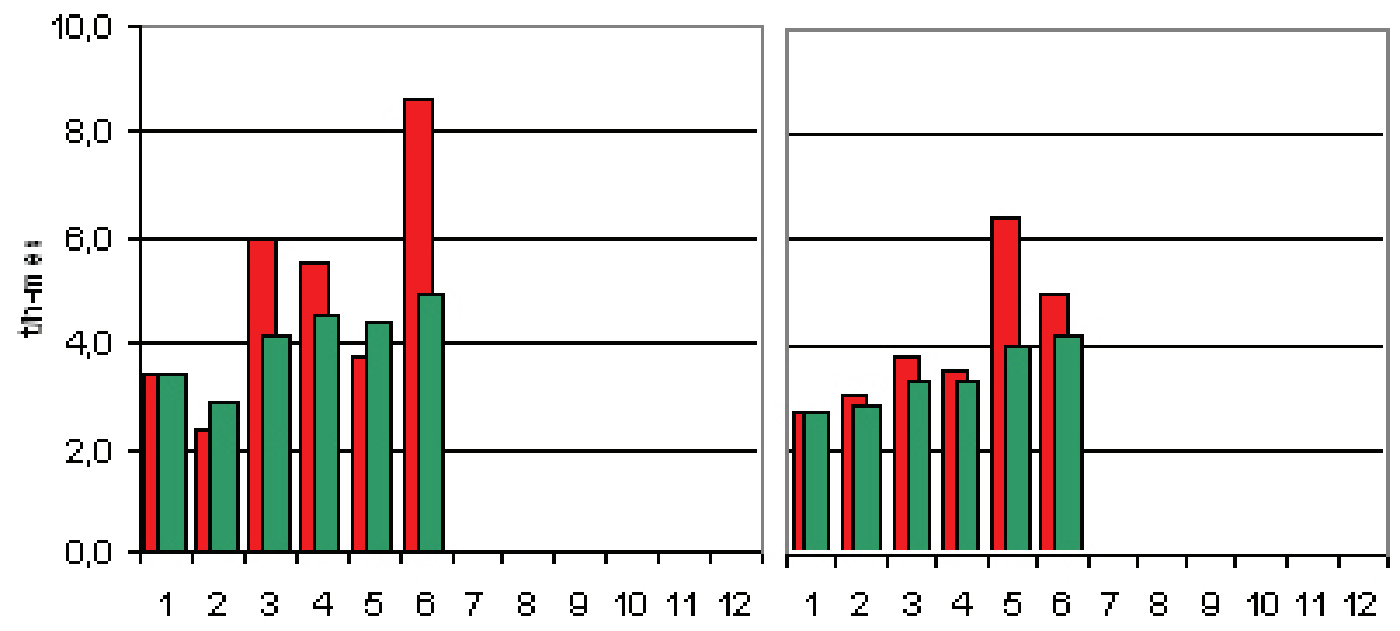

Figura 4: Comparação da produtividade no enfardamento nos primeiros semestres de 2005 e 2006.

Considerando que o número de funcionários foi basicamente o mesmo, observou-se um desempenho inferior ao do ano passado. 


\section{CONSIDERAÇÕES FINAIS}

Baseado na análise dos indicadores de performance avaliados alguns pontos podem ser apontados:

- Relação menos consistente entre a quantidade de embalagens recebidas e enfardadas no ano de 2006, com conseqüente redução no número de cargas de Pead expedidas neste ano.

- Menor eficiência entre materiais recebidos e enfardados em 2006.

- Redução na capacidade de enfardamento, conseqüência da redução do enfardamento por tonelada/homem e homens/mês acumulados no mesmo ano.

- Menor desempenho da Central em 2006.

\section{REFERÊNCIAS}

CORRÊA, H.L.; CORRÊA, C.A. Administração de produção e de operações. São Paulo: Atlas, 2005.

GERASSI, P.V.M. (elab.). Manual de destinação final de embalagens vazias de produtos fitossanitários. In: VIANA, E.E.S. Avaliação da destinação final de embalagens vazias de agrotóxicos. Ituverava: FE/FAFRAM, dez.2005. p.20-21/26. Trabalho de Conclusão de Curso (Graduação em Engenharia Agronômica). Faculdade "Dr. Francisco Maeda". Fundação Educacional de Ituverava.

INSTITUTO NACIONAL DE PROCESSAMENTO DE EMBALAGENS VAZIAS - inpEV. Quadro de Medição. Barueri: inpEV, 2004. (em cooperação com ATM - Consultoria e Gerenciamento de Projetos S/C Ltda).

INSTITUTO NACIONAL DE PROCESSAMENTO DE EMBALAGENS VAZIAS - inpEV. Relatório Anual do Instituto Nacional de Processamento de Embalagens Vazias 2005. São Paulo: inpEV, 2006.

INSTITUTO NACIONAL DE PROCESSAMENTO DE EMBALAGENS VAZIAS inpEV. Identificação das embalagens. In: VIANA, E.E.S. Avaliação da destinação final de embalagens vazias de agrotóxicos. Ituverava: FE/FAFRAM, dez.2005. p.20-21/26. Trabalho de Conclusão de Curso (Graduação em Engenharia Agronômica). Faculdade "Dr. Francisco Maeda”. Fundação Educacional de Ituverava.

MAXIMIANO, A.C.A. Introdução à administração. São Paulo: Atlas, 2000.

MIRANDA, A.T. Quadro de medição. Barueri, 2004. (ATM - Consultoria e Gerenciamento de Projetos S/C Ltda).

Nucleus, v. 5. n. 1 , abr. 2008 
NEELY et al. Performance measurement system design. In: CORREA, H.L.; CORREA, C.A. Administração de produção e de operações. São Paulo: Atlas, 2005.

PONTES, B.R. Avaliação de desempenho: uma abordagem sistêmica. São Paulo: LTr, 1991.

ROCHA, E. F. R. da. Avaliação de resíduos em embalagens vazias de agrotóxicos após diferentes lavagens sob pressão. In: VIANA, E.E.S. Avaliação da destinação final de embalagens vazias de agrotóxicos. Ituverava: FE/FAFRAM, dez.2005. p.20-21/26. Trabalho de Conclusão de Curso (Graduação em Engenharia Agronômica). Faculdade "Dr. Francisco Maeda". Fundação Educacional de Ituverava.

SLACK N. et al. Administração da produção. São Paulo: Atlas, 1999. 